\title{
"Happy days are here again"
}

\author{
Lotte Cash
}

"Happy days are here again. The skies above are clear again. So let's sing a song of cheer again. Happy days are here again."

I can't remember when I was in such a good mood about general practice. Well, actually I can. It was about 10 years ago when our practice was fund-holding and we were awash with cash.

In the National Health Service (NHS) the wheel just keeps on turning and ideas, and of course patients, come and go and come back again. In April this year the big wheel brought general practitioner (GP) fund-holding back again. I know it's being called practice-based commissioning (PBC), but let's be honest, it's fund-holding with a different name. In fact, talking of wheels turning, I must give the gym equipment supplier a call.

You see our patient gym really needs upgrading - the one we installed in the 1990s using fund-holding savings and we haven't been able to do it because there's been a paucity of funding schemes of late. But that's all changing and I'm finding it difficult to contain my excitement since PBC, as it's called, offers so many opportunities. We've already got planning permission to extend our practice to accommodate a bigger and better gym - we'll use PBC savings to finance this. This will mean we'll be able to cram more of our obese, heart disease, and diabetic patients into the weight-management classes. In turn this will help us achieve our 'Quality and Outcomes Framework' (QoF) points and we'll save money into the bargain because if these patients need a consultant opinion they can see a consultant at the practice as we'll be employing them with savings too. So, for the patient a quicker service, for the NHS a cheaper service - that's quite catchy, I think I'll record it for our call-waiting service. Bottom line: our

J Fam Plann Reprod Health Care 2006; 32(2): 132

Wrewardingsmee, UK

Lotte Cash, MRcGP, General Practitioner patients will be happier because they won't have to wait so long or travel so far, and we'll be happy because there'll be no need to use 'Choose and Book' and we'll be quids in.

Oh, it's going to be great. I won't have to disappoint my kids by telling them that we can't afford to go to Disneyworld because I've had to spend our family holiday savings on a defibrillator for the practice - a vital piece of equipment since we'll be having more at-risk patients undergoing lifestyle programmes in house. PBC savings can pay for it now. And what an opportunity to finally silence those who want GPs to provide the full range of sexual health services in primary care. Those upstairs have been telling us we should be doing this, despite the fact that we would have to resource it ourselves, financially and with our own time. Well, you asked for it, and now you're going to get it. I'm sorry, but the fact that I'll be pinching staff from the local genitourinary medicine clinic to run it leaving them metaphorically 'up the duff' is their problem, not mine.

Come to think of it, they say that being a doctor would be the perfect job if it weren't for the patients. Well now it can be perfect. If I employ other people to see my patients then I won't have to. Hospital consultants, complementary therapists, counsellors and a life coach should be able to handle most things. From what I read it won't be long before these people become self-financing since the 'Payment by Results' hospital tariff means they will be cheaper than the cost of a hospital appointment - another bonus.

Surely I must be dreaming? Can it get any better? Well apparently yes it can, since I'm writing this at my local Porsche showroom while waiting for my consultation with the dealer. There is a nagging doubt in my mind, however, and that's what colour to have for my soon-to-be-registered 'urgent patient transport vehicle'? Should I have blue since that team set this ball in motion by introducing GP fundholding in the first place, or should I have red since that team have been kind enough to bring it back?

\section{Book Reviews}

Contraception. A Kubba. London, UK: Mosby, 2005. ISBN: 0-72-343361-5. Price: £11.99. Pages: 122 (paperback)

In the introduction of this new manual, the author poses the question whether yet another new reference book on contraception was required. Obviously the publisher's answer was 'Yes'.

I therefore read this book with great interest, and particularly asked myself how this book was different from the myriad similar publications on the market. I am pleased to report that this book is different and has many points to recommend it.

First, it truly is a pocket-sized reference book and is therefore extremely portable. Clearly this is not a reference book that is meant to be left on the bookshelf; it could easily be kept literally in your pocket whilst working.

Second, it is very well laid out. There is a chapter on each method and these are subdivided in a concise and user-friendly manner. I particularly liked the subsections on "evidence to watch for", which briefly discussed future developments. Also, "counselling points" concisely listed the pertinent points that should be discussed with each patient. In fact, the whole tone of this publication was very patientorientated, with good communication and an empathic approach clearly of paramount importance to the author.

The first chapter of the book particularly deals with the approach to different groups of clients (e.g. adolescents, perimenopausal women) and their particular needs. Two other sections of this book that I found particularly helpful were the section on "frequently asked questions (FAQs)" and also the WHO medical eligibility criteria for contraceptive use. It is clear from the responses to the FAQs that the author is an excellent communicator with his patients. This is also apparent from his way of communicating risk and putting risk into perspective in a patientfriendly manner. The appendix containing the WHO medical eligibility criteria is extremely useful and further adds to the appeal of this pocket-sized manual.

Unfortunately there were also a few disappointments with this book. A few typographical errors, poor punctuation and poor sentence construction point to poor editing. It was also clear that this manual is aimed at a North American market, as there were some references to the current management there (e.g. that the "USA FDA recommend a Pap smear three months after cap use"). This was unhelpful and potentially confusing. If I were recommending this manual to my trainees I would forewarn them about this.

Despite the above caveats, I would recommend this manual to family planning trainees and experienced doctors alike. It is concise, evidence-based and written in a fresh and novel style.

Reviewed by Ailsa Wylie, MRCOG, MFFP Staff Grade in Reproductive Health Care, Edinburgh, UK 